\title{
HUBUNGAN PENGAWASAN INFECTION PREVENTION AND CONTROL LINK NURSE (IPCLN) TERHADAP KEPATUHAN PERAWAT MELAKUKAN CUCI TANGAN DI RUANG RAWAT INAP MURNI TEGUH MEMORIAL HOSPITAL
}

\author{
Seriga Banjarnahor, Aruna Ragini \\ Program Studi Ilmu Keperawatan STIKes Murni Teguh, Murni Teguh Memorial Hospital \\ E-mail: serigabanjarnahor@yahoo.com, arunaragini@yahoo.com
}

\begin{abstract}
Healthcare Associated Infections (HAIs)/ Nosocomial infections is a mayority problem in Hospital caused by hand contact. Hand washing is a one of the effective simple strategy to prevent Healthcare Associated Infections (HAIs)/Nosocomial Infection. Hospital and the other care facilities are required to have a IPCN (Infection Prevention and Control Link Nurese). In IPCN work assisted by several IPCLN (Infection Prevention and Control Link Nurse). Strategy to improve a quality of nursing services is very important to do optimize the compliance of nurse by hand washing supervision or suvervisi wich focuses to improving a quality of nursing care. This study aims to determine the relationship of control Infection Prevention and Control Link Nurse 9IPCLN) to compliance of handwasing nurse to patinet room in Murni Teguh Memorial Hospital Medan. The results showed that IPCLN survalliance at Murni Teguh Memorial Hospital Medan was generally poor is 24 respondents (70,59\%) less good an dgood is 7 respondent (20,59\%). The conclution of this study is the controlof Infrction Prevention and Control Link Nurse (IPCLN) has significant relationship to the compliance of nurse perform handwashing in the inpatient room at Murni Teguh Memorial Hospital Medan.
\end{abstract}

Keywords: Supervision of IPCLN, Handwashing compliance

\begin{abstract}
Abstrak
Healthcare Associated Infections (HAIs) / Infeksi Nosokomial merupakan masalah besar yang dihadapi rumah sakit, dapat disebarkan melalui kontak tangan. Cuci tangan merupakan salah satu cara yang paling sederhana dan efektif untuk mencegah terjadinya Infeksi Nosokomial. Rumah Sakit dan fasilitas pelayanan kesehatan lainnya wajib memiliki IPCN (infection Prevention and Control Nurse), dalam bekerja IPCN dibantu beberapa IPCLN (Infection Prevention and Control Link Nurse). Upaya peningkatan kualitas pelayanan keperawatan yang sangat penting dilakukan untuk mengoptimalkan kepatuhan perawat dalam melakukan cuci tangan adalah adanya pengawasan atau suvervisi yang berfokus terhadap peningkatan kualitas dan mutu pelayanan keperawatan.Penelitian ini bertujuan untuk mengetahui hubungan pengawasan Infection Prevention and Control Link Nurse (IPLCN) terhadap kepatuhan cuci tangan perawat di ruang rawat inap Murni Teguh Memorial Hospital Medan. Hasil penelitian menunjukkan bahwa pengawasan IPCLN di Murni Teguh Memorial Hospital Medan umumnya kurang baik, dimana sebanyak 24 responden $(70,59 \%)$ kurang baik, sedangkan pengawasan IPCLN baik sebanyak 10 responden $(29,41 \%)$. Kepatuhan perawat melakukan cuci tangan di ruang rawat inap tergolong kurang baik yaitu sebanyak 27 responden $(79,41 \%)$ dan baik hanya sebanyak 7 responden $(20,59 \%)$. Kesimpulan penelitian ini adalah ada hubungan yang signifikan antara pengawasan Iinfection Prevention and Control Link $(I P C L N)$ terhadap kepatuhan perawat melakukan cuci tangan di ruang rawat inap Murni Teguh Memorial Hospital.
\end{abstract}

Kata kunci : Pengawasan IPCLN, Kepatuhan cuci tangan 


\section{PENDAHULUAN}

Infeksi atau yang sekarang disebut sebagai infeksi yang berhubungan dengan pelayanan kesehatan atau Health-care Associated Infection (HAIs) merupakan masalah penting di seluruh dunia yang meningkat (Depkes RI, 2012). Saat ini, tingkat infeksi yang terjadi di beberapa Negara Eropa dan Amerika masih rendah yaitu sekitar $1 \%$ dibandingkan dengan kejadian di Negara-Negara Asia, Amerika Latin dan Sub-Sahara Afrika yang tinggi hingga mencapai lebih dari $40 \%$ dan menurut data WHO, angka kejadian infeksi di rumah sakit di Negara-negara Asia sekitar 3-21\% (rata-rata 9\%) Depkes, 2012). Angka infeksi nosokomial terus meningkat (Al Varado, 2000) mencapai sekitar $9 \%$ (variasi $3-21 \%$ ) atau lebih dari 1,4 juta pasien rawat inap di rumah sakit seluruh dunia. Data infeksi nosokomial di Indonesia sendiri dapat dilihat dari data surveilans yang dilakukan oleh Kementrian Kesehatan RI pada tahun 2013 di 10 RSU Pendidikan, diperoleh angka infeksi nosokomial cukup tinggi yaitu sebesar 6-16\% dengan rata-rata 9,8\% pasien rawat inap mendapat infeksi baru selama dirawat (Kemenkes, 2013).

Berdasarkan hasil survey penelitian yang dilakukan Sukartik (2009) di Rumah Sakit Sumatera Utara tentang kejadian infeksi nosokomial, data di Rumah Sakit Umum Daerah Dr Pirngadi Kota Medan Tahun 2009 terhadap infeksi nosokomial di ruang rawat inap sebesar 2,63\% yang terdiri dari infeksi yang disebabkan oleh penggunaan jarum infus sebesar $1,8 \%$, angka infeksi luka operasi sebesar $0,8 \%$, dan tranfusi darah $0,03 \%$. Dan data yang diperoleh dari Komite Pencegahan dan Pengendalian Infeksi Murni Teguh memorial Hospital Medan pada tahun 2015 angka Infeksi Saluran Kemih (ISK) sebesar 0,5\%o, Phlebitis sebesar $0,65 \%$ dan Ventilator Associated Pneumonia (VAP) sebesar $23,5 \%$.

Infeksi nosokomial didapatkan selama pengobatan medis, meskipun banyak infeksi yang terjadi pada pasien, infeksi didapatkan pada saat bekerja oleh pelayan kesehatan juga termasuk infeksi nosokomial (Black, 2012). Salah satu bagian dari pelayanan keperawatan yang dapat berpengaruh pada masyarakat adalah perilaku cuci tangan perawat sebagai salah satu bentuk pencegahan infeksi. Kebersihan tangan adalah ukuran utama untuk mengurangi infeksi. WHO mencetuskan global patient safety challenge dengan clean care is safe care, yaitu merumuskan inovasi strategi penerapan hand hygiene untuk petugas kesehatan dengan five moment for Hand Hygiene. Five moment for hand hygiene adalah 5 momen krusial mencuci tangan pada petugas kesehatan untuk mengoptimalkan kebersihan tangan dengan mencuci tangan di saat : sebelum kontak dengan pasien, sebelum melakukan tindakan aseptik/prosedur bersih/steril, setelah bersentuhan dengan cairan tubuh pasien, dan setelah kontak / bersentuhan dengan benda dan lingkungan pasien (WHO, 2006).

Studi di Amerika Serikat menunjukkan tingkat kepatuhan perawat melakukan cuci tangan masih sekitar 50\% dan di Australia masih sekitar 65\%. Sama halnya dengan program cuci tangan di Rumah Sakit Cipto Mangunkusumo (RSCM) yang sudah sejak tahun 2008 tetapi sampai saat ini kepatuhan perawat melakukan cuci tangan hanya sekitar 60\%. Data yang diperoleh dari Rumah Sakit Haji Adam Malik Medan tahun 2014 kepatuhan perawat melakukan cuci tangan sebesar $44,31 \%$. Hal ini bisa menjadi tantangan yang cukup besar bagi tim pengendali infeksi rumah sakit untuk mempromosikan program cuci tangan ini. (Perdalin, 2010).

Berdasarkan latar belakang diatas maka penulis tertarik untuk melakukan penelitian tentang "Hubungan Pengawasan Infection Prevention and Control Link Nurse (IPCLN) terhadap Kepatuhan cuci tangan perawat di ruang rawat inap Murni Teguh Memorial Hospital Medan. 
Permasalahan yang akan diteliti adalah : permasalahan indikator mutu Komite PPI lebih tinggi dari tingkat kepatuhan cuci tangan perawat di rumah sakit sehingga perlu pengawasan Infection Prevention and Control Link Nurse (IPLCN) terhadap kepatuhan cuci tangan perawat di ruang rawat inap Murni Teguh Memorial Hospital Medan.

Untuk mengetahui hubungan pengawasan Infection Prevention and Control Link Nurse (IPLCN) terhadap kepatuhan cuci tangan perawat di ruang rawat inap Murni Teguh Memorial Hospital Medan.

\section{METODE PENELITIAN}

Desain penelitian yang digunakan dalam penelitian ini adalah korelasi. Penelitian ini dilaksanakan pada tanggal 18 Januari - 8 Februari 2017 yang berlokasi di Murni Teguh Memorial Hospital Medan. Populasi dalam penelitian ini adalah perawat pelaksana di 2 ruangan rawat inap Murni Teguh Memorial Hospital sebanyak 34 orang. Dalam penelitian ini seluruh populasi dijadikan sampel, sehingga penelitian ini menggunakan teknik total sampling. Adapun jumlah sampel ditetapkan sebanyak 34 orang.

Teknik analisa data dengan univariat dan bivariat adalah suatu analisis yang bersifat untuk melihat hubungan antara dua variabel yaitu variabel bebas (pengawasan Infection Prevention ang Control Link Nurse (IPCLN)) dengan variabel terikat (kepatuhan perawat melakukan cuci tangan) dengan menguji penerimaan atau penolakan hipotesis penelitian ini maka dapat dilihat dari hasil penelitian yang menunjukkan bahwa :

a. Ho ditolak dan Ha diterima, yaitu nilai $\mathrm{X}^{2}$ hitung $>\mathrm{X}^{2}$ tabel atau nilai probabilitas $(\mathrm{p})<0,05$, maka ada hubungan pengawaasan Infection and Prevention Control Link Nurse (IPCLN) terhadap kepatuhan perawat melakukan cuci tangan.

b. Ho diterima dan Ha ditolak, yaitu nilai $\mathrm{X}^{2}$ hitung $<\mathrm{X}^{2}$ tabel atau nilai probabilitas $(p)>0,05$, maka tidak ada hubungan pengawaasan Infection and Prevention Control Link Nurse (IPCLN) terhadap kepatuhan perawat melakukan cuci tangan.

\section{HASIL PENELITIAN}

Karakteristik Responden

Karakteristik responden berdasarkan usia, jenis kelamin, masa kerja dan pendidikan :

\begin{tabular}{|c|c|c|c|}
\hline No & $\begin{array}{c}\text { Karakteristik } \\
\text { Responden }\end{array}$ & $\begin{array}{c}\text { Frekuensi } \\
\text { (jumlah) }\end{array}$ & $\begin{array}{c}\text { Persentase } \\
(\%)\end{array}$ \\
\hline \multirow[t]{4}{*}{1} & Usia $<25$ tahun & 22 & \\
\hline & $25-30$ & 11 & 64,71 \\
\hline & tahun & 1 & 32,35 \\
\hline & $>30$ tahun & & 2,94 \\
\hline \multirow[t]{3}{*}{2} & Jenis Laki-Laki & - & - \\
\hline & Kelam Perempuan & 34 & 100,0 \\
\hline & in & & 0 \\
\hline \multirow[t]{3}{*}{3} & Masa $<1$ tahun & 2 & 5,88 \\
\hline & Kerja $1-2$ tahun & 27 & 79,41 \\
\hline & $>3$ tahun & 5 & 14,71 \\
\hline \multirow[t]{3}{*}{4} & Pendi S1 & 5 & 14,71 \\
\hline & dikan D3 & 29 & 85,29 \\
\hline & Total & 34 & 100,00 \\
\hline
\end{tabular}

Berdasarkan tabel di atas, diketahui bahwa mayoritas responden perawat berusia di bawah 25 tahun yaitu sebanyak 22 orang $(64,71 \%)$, usia 25 30 tahun sebanyak 11 orang $(32,25 \%)$ dan di atas 30 tahun sebanyak 1 orang $(2,94 \%)$.

Keseluruhan responden perawat berjenis kelamin perempuan dengan mayoritas masa kerja $1-2$ tahun sebanyak 27 orang $(79,41 \%)$, masa kerja di bawah 1 tahun sebanyak 2 orang $(5,88 \%)$ dan masa kerja di atas 3 tahun sebanyak 5 orang $(14,71 \%)$.

Sebagian besar perawat berpendidikan D3 sebanyak 29 orang $(85,92 \%)$, sedangkan berpendidikan S1 sebanyak 5 orang $(14,71 \%)$.

\begin{tabular}{|c|c|c|c|}
\hline \multicolumn{4}{|c|}{$\begin{array}{l}\text { Pengawasan Infection Prevention and } \\
\text { Control Link Nurse (IPCLN) di Murni } \\
\text { Teguh Memorial Hospital Medan }\end{array}$} \\
\hline $\begin{array}{l}\mathbf{N} \\
\mathbf{0}\end{array}$ & $\begin{array}{l}\text { Pengawa- } \\
\text { san } \\
\text { IPCLN }\end{array}$ & $\begin{array}{c}\text { Frekue- } \\
\text { nsi } \\
\text { (jumlah } \\
\text { ) }\end{array}$ & $\begin{array}{l}\text { Persen- } \\
\text { tase } \\
(\%)\end{array}$ \\
\hline
\end{tabular}




\begin{tabular}{|c|c|c|c|}
\hline 1 & Baik & 10 & 29,41 \\
\hline 2 & $\begin{array}{l}\text { Kurang } \\
\text { Baik }\end{array}$ & 24 & 70,59 \\
\hline & & 34 & $\begin{array}{c}100 \\
00\end{array}$ \\
\hline
\end{tabular}

Berdasarkan tabel di atas, diketahui bahwa pengawasan IPCLN di Murni Teguh Memorial Hospital Medan umumnya kurang baik, dimana sebanyak 24 responden $(70,59 \%)$ kurang baik, sedangkan pengawasan IPCLN baik sebanyak 10 responden $(29,41 \%)$.

Hasil penelitian menunjukkan bahwa pengawasan IPCLN yang dilakukan di Murni Teguh Memorial Hospital Medan masih kurang baik, sehingga perlu ditingkatkan menjadi baik, dimana pengawasan IPCLN ini sangat penting dalam menjamin kebersihan dan higienitas perawat dan rumah sakit.

\section{Kepatuhan Perawat Melakukan Cuci Tangan}

di Ruang Rawat Inap Murni Teguh

Memorial Hospital Medan

\begin{tabular}{|c|c|c|c|}
\hline $\mathbf{N}$ & $\begin{array}{c}\text { Kepatuhan } \\
\text { Perawat } \\
\text { Melakukan } \\
\text { Cuci Tangan }\end{array}$ & $\begin{array}{c}\text { Freku } \\
\text { ensi } \\
(\text { jumla } \\
\text { h) }\end{array}$ & $\begin{array}{c}\text { Persentase } \\
(\%)\end{array}$ \\
\hline 1 & Baik & 7 & 20,59 \\
\hline 2 & Sedang & $\begin{array}{l}1 \\
8 \\
\end{array}$ & 52,94 \\
\hline 3 & Buruk & 9 & 26,47 \\
\hline & Total & $\begin{array}{l}3 \\
4 \\
\end{array}$ & 100,00 \\
\hline
\end{tabular}

Berdasarkan tabel di atas, diketahui bahwa kepatuhan perawat melakukan cuci tangan di ruang rawat inap tergolong buruk yaitu sebanyak 9 responden $(26.47 \%)$, sedang sebanyak 18 responden $(52,94 \%)$ dan baik hanya sebanyak 7 responden $(20,59 \%)$.

Hasil penelitian ini menunjukkan bahwa tingkat kepatuhan perawat melakukan cuci tangan di ruang rawat inap masih tergolong kurang baik. Hal ini dapat mengkibatkan masalah pada kebersihan dan higienitas perawat yang selanjutnya akan berakibat negatif tehadap pasien yang berada pada ruang rawat inap tersebut.

\section{Hubungan Pengawasan Infection Prevention and Control Link Nurse (IPCLN) terhadap Kepatuhan Perawat Melakukan Cuci Tangan di Ruang Rawat Inap Murni Teguh Memorial Hospital Medan}

\begin{tabular}{|c|c|c|c|c|c|c|c|c|}
\hline \multirow{3}{*}{$\begin{array}{l}\text { Penga } \\
\text { wasan } \\
\text { IPCL } \\
\text { N }\end{array}$} & \multirow{2}{*}{\multicolumn{6}{|c|}{$\begin{array}{l}\text { Kepatuhan Pe } \\
\text { Melakukan Cuci Tangan }\end{array}$}} & \multirow{3}{*}{$\begin{array}{l}\mathrm{Ju} \\
\mathrm{mla} \\
\mathrm{h}\end{array}$} & \multirow{3}{*}{$\begin{array}{l}\mathrm{P} \\
\text { valu } \\
\mathrm{e}\end{array}$} \\
\hline & & & & & & & & \\
\hline & $\begin{array}{l}\text { Bai } \\
\mathrm{k}\end{array}$ & $\%$ & $\begin{array}{l}\mathrm{Bu} \\
\text { ruk }\end{array}$ & $\%$ & $\begin{array}{l}\text { Se } \\
\text { dan }\end{array}$ & $\%$ & & \\
\hline Baik & 7 & $\begin{array}{l}20, \\
59\end{array}$ & 1 & $\begin{array}{l}2,9 \\
4\end{array}$ & $\begin{array}{l}\mathrm{g} \\
2\end{array}$ & $\begin{array}{l}5,8 \\
8 \\
\end{array}$ & 10 & 0,0 \\
\hline $\begin{array}{l}\text { Kuran } \\
\text { g Baik }\end{array}$ & 0 & 0 & 8 & $\begin{array}{l}23, \\
53\end{array}$ & $\begin{array}{l}1 \\
6\end{array}$ & $\begin{array}{l}47, \\
06\end{array}$ & 24 & 00 \\
\hline Total & 7 & $\begin{array}{l}20, \\
59\end{array}$ & 9 & $\begin{array}{l}26, \\
47\end{array}$ & $\begin{array}{l}1 \\
8 \\
\end{array}$ & $\begin{array}{l}52, \\
94\end{array}$ & 34 & \\
\hline
\end{tabular}

Berdasarkan tabel di atas, diketahui bahwa pengawasan IPCLN yang baik memberikan kepatuhan perawat melakukan cuci tangan yang baik di ruang rawat inap sebanyak 7 orang $(20,59 \%)$, kepatuhan sedang sebanyak 1 orang $(2,94 \%)$ dan kepatuhan buruk sebanyak 2 orang $(5,88 \%)$. Pengawasan IPCLN yang kurang baik menyebabkan kepatuhan perawat melakukan cuci tangan yang sedang sebanyak 16 orang $(47,06 \%)$ dan kepatuhan buruk sebanyak 8 orang $(23,53 \%)$. Hal ini menunjukkan bahwa dengan adanya pengawasan IPCLN belum tentu dapat menimbulkan kepatuhan perawat melakukan cuci tangan, sehingga kesadaran perawat melakuan cuci tangan di ruang rawat inap masih tergolong rendah.

\section{PEMBAHASAN}

Pengawasan Infection Prevention and Control Link Nurse (IPCLN) di Murni Teguh Memorial Hospital Medan

Hasil penelitian menunjukkan bahwa pengawasan IPCLN di Murni Teguh Memorial Hospital Medan umumnya kurang baik, dimana sebanyak 24 responden $(70,59 \%)$ kurang baik, sedangkan pengawasan IPCLN baik sebanyak 10 responden $(29,41 \%)$. Hal ini menunjukkan bahwa proses pengawasan IPCLN yang dilakukan 
belum terlaksana dengan baik. Disamping itu hasil pengawasan yang kurang baik juga dipengaruhi oleh kinerja IPCLN. Untuk meningkatkan kemampuan maka dapat dilakukan pelatihan sesuai dengan programprogramnya. Semua IPCLN yang telah dipilih oleh manajemen rumah sakit tentunya didasarkan pada tingkat kemampuan, pendidikan dan mempunyai jiwa leadership sehubungan dengan tugasnya sebagai motivator bagi rekan-rekan kerjanya di unit tempat mereka bertugas. Menurut pendapat Simanjuntak (2011) pengalaman kerja akan mempengaruhi kemampuan dan ketrampilan kerja setiap orang selain kebugaran fisik, kesehatan jiwa, pendidikan dan akumulasi pelatihan. Pengalaman kerja dapat memperluas dan memperdalam kemampuan kerja. Semakin sering seseorang melakukan pekerjaan yang sama, semakin trampil dan semakin cepat dia menyelesaikan pekerjaan tersebut.

Tugas-tugas IPCLN memerlukan kemampuan dan ketrampilan khusus agar program pengawasan berlangsung dengan baik. Menurut Simanjuntak (2011) semakin lama waktu yang digunakan untuk pendidikan dan pelatihan, semakin tinggi kemampuan dan kompetensinya melakukan pekerjaan, dengan demikian pengawasan yang dilakukan oleh IPCLN juga semakin baik. Hasil penelitian terdahulu yang dilakukan oleh Farooq dan Aslam Khan (2011) pada institusi pendidikan di Pakistan, menyimpulkan training (pelatihan) berpengaruh signifikan terhadap employee performance (kinerja pegawai) bersama-sama dengan variabel feedback (umpan balik). Training dan feedback berdampak pada peningkatan kinerja karyawan. Pelatihan mempunyai berbagai manfaat untuk karier jangka panjang yang membantu IPCLN mempunyai tanggungjawab lebih besar dalam jangka waktu yang panjang. Program-program pelatihan tidak hanya penting bagi individu tetapi juga bagi organisasi di rumah sakit.
Menurut Depkes dan Perdalin (2008) bahwa berhasil tidaknya pengawasan yang dilakukan IPCLN dipengaruhi oleh berbagai faktor diantaranya kemampuan kerja, keterampilan kerja dan dukungan organisasi. Kriteria seorang yang bekerja sebagai IPCLN :

1. Perawat dengan pendidikan min D3 dan memiliki sertifikasi PPI.

2. Memiliki komitmen di bidang pencegahan dan pengendalian infeksi.

3. Memiliki kemampuan leadership. IPCLN sebagai perawat pelaksana harian / penghubung bertugas :

1. Mengisi dan mengumpulkan formulir surveilans setiap pasien di unit rawat inap masing-masing, kemudian menyerahkan-nya kepada IPCN ketika pasien pulang.

2. Memberikan motivasi dan teguran tentang pelaksanaan kepatuhan pencegahan dan pengendalian infeksi pada setiap personil ruangan di unit rawatnya masing-masing.

3. Memberitahukan kepada IPCN apabila ada kecurigaan adanya infeksi nosokomial pada pasien.

4. Berkoordinasi dengan IPCN saat terjadi infeksi potensial KLB, penyuluhan bagi pengunjung di ruang rawat masingmasing, konsultasi prosedur yang harus dijalankan bila belum faham.

5. Memonitor kepatuhan petugas kesehatan yang lain dalam menjalankan Standar Isolasi.

Dari hasil penelitian tersebut dapat diketahui bahwa petugas IPCLN yang menjalankan tugasnya berlangsung berjalan dengan baik, dimana proses pengawasan yang dilakukan masih kurang baik. Hal ini terjadi karena jarangnya diadakan sosialiasi program melalui pendidikan dan pelatihan yang berkaitan dengan bimbingan teknis dan administrasi program. Sebagian IPCLN di beberapa ruang rawat inap yang sudah pernah mendapatkan pelatihan dan sosialisasi mengalami pergantian tugas karena mutasi/pindah bagian lain atau pindah ke rumah sakit lainnya, sehingga kesinambungan kegiatan pengumpulan 
data dilanjutkan oleh perawat pengganti yang belum mendapatkan sosialisasi program sehingga tidak sesuai SPO dan pedoman yang berlaku. Hal ini akan mempengaruhi pengawasan yang dilakukan oleh perawat IPCLN, dimana data-data yang dikumpulkan menjadi kurang lengkap.

Perawat IPCLN yang terlatih (bersertifikat pelatihan PPI Dasar) belum melakukan pengawasan terhadap tindakan-tindakan yang menyimpang dari standar prosedur dan memonitor proses terhadap IPCLN di ruang rawat inap, karena kesibukan merangkap tugas lain. Menurut Griffiths et all (2008), faktor yang berpengaruh dalam risiko terjadinya penurunan kinerja salah satunya yaitu beban kerja yang tidak sesuai dengan staf/perawat yang tersedia. Sedangkan menurut Yang (2003) dalama Amstrong (2009) mengemukakan bahwa beban kerja perawat merupakan indikator yang mengakibatkan terjadinya penurunan kinerja. Hal tersebut didukung oleh penelitian Nontji (2009) yang berjudul " Hubungan beban kerja dengan kinerja perawat pelaksana di Ruang Rawat Inap Medikal Bedah RSU Labuang Baji Makassar". Yang menunjukkan bahwa ada hubungan yang bermakna antara beban kerja dengan kinerja perawat. Komite PPI belum mengidentifikasi temuan penyimpangan SPO pelaksanaan tugas IPCLN di lapangan dan belum mengusulkan program pelatihan untuk meningkatkan sumber daya manusia perawat $I P C L N$.

\section{Kepatuhan Perawat Melakukan Cuci Tangan di Ruang Rawat Inap Murni Teguh Memorial Hospital Medan}

Hasil penelitian menunjukkan bahwa kepatuhan perawat melakukan cuci tangan di ruang rawat inap tergolong buruk yaitu sebanyak 9 responden (26.47 \%), sedang sebanyak 18 responden $(52,94 \%)$ dan baik hanya sebanyak 7 responden (20,59\%).

Kepatuhan perawat dalam mencuci tangan kurang baik terutama mencuci tangan dengan hand rub dengan alkohol memiliki tingkat kepatuhan yang rendah karena sebagian besar perawat berkeyakinan air lebih hygiene dari pada alkohol (Pan, et al., 2007). Meningkatkan pengetahuan perawat saja tidak cukup untuk merubah kepatuhan dalam melaksanakan cuci tangan, untuk meningkatnya pengetahuan tidak menjamin meningkatnya kepatuhan dalam pelaksanaan mencuci tangan (Tietjen, et al., 2004).

Peralatan yang dibutuhkan untuk mencuci tangan biasa adalah setiap wastafel dilengkapi dengan peralatan cuci tangan sesuai standar rumah sakit (misalnya kran air bertangkai panjang untuk mengalirkan air bersih, tempat sampah injak tertutup yang dilapisi kantung sampah medis atau kantung plastik berwarna kuning untuk sampah yang terkontaminasi atau terinfeksi), alat pengering seperti tissue, lap tangan (hand towel), sarung tangan (gloves), sabun cair atau cairan pembersih tangan yang berfungsi sebagai antiseptik, lotion tangan, serta di bawah wastefel terdapat alas kaki dari bahan handuk (Oliverira, et al., 2010).

Pencegahan infeksi dapat dilakukan dengan perilaku yang benar pada saat petugas kesehatan melakukan tindakan ke pasien, adanya prosedur yang baik sangat berperan dalam membentuk perilaku yang benar, namun demikian akan menjadi hambatan dalam pelaksanaan apabila fasilitas cuci tangan dengan air mengalir yang terbatas atau bahkan kurang tersedia. Berdasarkan hasil penelitian, sebagai bentuk dukungan rumah sakit terhadap fasilitas dengan keterbatasan sarana cuci tangan dengan air mengalir dapat menggunakan handrub, disetiap sudut ruangan sudah disediakan handrub lengkap dengan petunjuk 6 langkah mencuci tangan. Handrub tidak hanya disediakan untuk perawat namun pengunjung dan keluarga pasien juga bisa menggunakannya karena di setiap sudut ruangan sudah disediakan.

Untuk tetap menjaga kepatuhan dalam pelaksanaan mencuci tangan maka supervisi dan sosialisasi harus 
tetap dilaksanakan. Hasil wawancara menunjukkan dalam hal supervisi telah dilakukan sekali satu bulan sekali oleh Komite PPI. Supervisi dilakukan dalam bentuk pengawasan terhadap tindakan mencuci tangan yang dilakukan oleh perawat. Pengadaan buku laporan ketertiban adalah salah satu bentuk supervisi yang dilakukan oleh Komite PPI selain pengawasan yang diharapkan mampu mengukur tingkat kepatuhan perawat. Kegiatan yang merupakan bagian integral dari supervisi dalam keperawatan mencakup pelaporan, pembagian tugas, pemberian arahan, pengamatan, penilaian, pembimbingan, dan pendidikan pekerja.

Tingkat kepatuhan perawat dalam melakukan cuci tangan di ruang rawat inap juga disebabkan oleh kurangnya sosialisasi. Kurangnya sosialisasi akan menyebabkan ketidaktahuan informasi. Untuk itu perlu digalakkan sosialisasi di setiap ruang rawat inap secara berkala. Sosialisasi dengan menggunakan poster kurang efektif dalam meningkatkan pengetahuan, sedangkan penggunaan video edukasi sangat efektif dalam menjaga kepatuhan petugas kesehatan dalam menerapkan universal precaution. Bahkan tidak hanya bagi petugas kesehatan, video edukasi sangat dirasakan pengaruhnya untuk pengunjung rumah sakit.

\section{Hubungan Pengawasan Infection Prevention and Control Link Nurse (IPCLN) terhadap Kepatuhan Perawat Melakukan Cuci Tangan di Ruang Rawat Inap Murni Teguh Memorial Hospital Medan}

Dari hasil uji Chi Square hubungan pengawasan Infection Prevention and Control Link Nurse (IPCLN) terhadap kepatuhan perawat melakukan cuci tangan di ruang rawat inap Murni Teguh Memorial Hospital Medan diperoleh nilai Chi Square sebesar 21,156 lebih besar dari Chi Square tabel sebesar 3,8415 sehingga dapat disimpulkan bahwa pengawasan Infection Prevention and Control Link Nurse (IPCLN) memiliki hubungan yang signifikan terhadap kepatuhan perawat melakukan cuci tangan di ruang rawat inap Murni Teguh Memorial Hospital Medan. Semakin baik pengawasan IPCLN yang dilakukan maka tingkat kepatuhan perawat dalam melakukan cuci tangan di ruang rawat inap akan semakin baik.

Pengawasan Infection Prevention and Control Link Nurse (IPCLN) memiliki hubungan yang signifikan terhadap kepatuhan perawat melakukan cuci tangan di ruang rawat inap Murni Teguh Memorial Hospital Medan, dimana semakin baik pengawasan IPCLN yang dilakukan maka tingkat kepatuhan perawat dalam melakukan cuci tangan di ruang rawat inap akan semakin baik. Untuk itu perlu dilakukan pengawasan yang lebih ketat terhadap perawat dalam melakukan cuci tangan karena merupakan salah satu penentu kualitas pelayanan keperawatan Adanya pengawasan atau suvervisi yang berfokus terhadap peningkatan kualitas dan mutu pelayanan keperawatan.

Walaupun proses pengawasan IPCLN masih kurang baik, tetapi memiliki hubungan yang signifikan terhadap kepatuhan perawat. Hal ini menunjukkan bahwa fungsi pengawasan harus tetap dilakukan untuk menghindari perawat di ruang rawat inap yang masih belum patuh dalam penerapan mencuci tangan. Kepatuhan juga dapat dipengaruhi oleh umur, pengalaman bekerja dan pelatihan. Keterbatasan pengawasan oleh IPCLN harus dapat diatasi untuk memperbaikan pelaksanaan pengawasan. Setiap ruangan dibentuk tim yang bertugas mengawasi kepatuhan perawat yang lain dalam penerapan mencuci tangan. Selain itu dapat juga dilakukan dengan tinjauan rekan sejawat yaitu penilaian dari rekan sejawat mengenai kepatuhan perawat. Tinjauan rekan sejawat jika diimplementasikan secara benar memberikan umpan balik yang berharga bagi perawat yang dapat meningkatkan kinerjanya serta membantu IPCLN dalam evaluasi kepatuhan perawat. Peningkatan kepatuhan yang dapat dilakukan adalah dengan memberikan 
kesempatan kepada perawat yang belum pernah mengikuti pelatihan untuk diikutsertakan dalam kegiatan tersebut, hal ini akan memberikan pengalaman dan pengetahuan tambahan sehingga perawat yang belum patuh dapat merubah prilakunya menjadi patuh dalam penerapan mencuci tangan di ruang rawat inap. Semakin tinggi tingkat pengawasan terhadap perawat maka perawat akan semakin patuh seseorang menjalankan instruksi tersebut. Menurut Susilo (2009) yang mengatakan seseorang berperilaku belum tentu didasarkan pada pengetahuan, seperti melakukan pencegahan penyakit tertentu mungkin dikarenakan seseorang tersebut merasa terancam akan terkena penyakit tersebut dan bukan karena pengetahuannya tentang penyakit.

Hasil penelitian ini didukung oleh hasil penelitian Saparwati dan Suswanto (2016) menyimpulkan bahwa ada hubungan kualitas supervisi kepala ruang terhadap kepatuhan perawat melakukan standar cuci tangan di instalasi rawat inap RST Dr. Soedjono Magelang $(p$ value $=0,005)$. Hasil penelitian ini juga didukung oleh penelitian Hanafiah (2015) yang menyimpulkan bahwa pengawasan kepala ruang di RSUD Wonosari memiliki hubungan yang signifikan dengan tingkat kepatuhan perawat.

\section{KESIMPULAN}

Dari hasil penelitian hubungan pengawasan IPCLN terhadap kepatuhan perawat melakukan cuci tangan di Ruang Rawat Inap Murni Teguh Memorial Hospital Medan, maka diperoleh kesimpulan sebagai berikut :

1. Pengawasan IPCLN di Murni Teguh Memorial Hospital Medan umumnya kurang baik, dimana sebanyak 24 responden $(70,59 \%)$ kurang baik, sedangkan pengawasan IPCLN baik sebanyak 10 responden $(29,41 \%)$.

2. kepatuhan perawat melakukan cuci tangan di ruang rawat inap tergolong buruk yaitu sebanyak 9 responden (26.47\%), sedang sebanyak 18 responden $(52,94 \%)$ dan baik hanya sebanyak 7 responden $(20,59 \%)$.

3. Dari hasil uji Chi Squre diperoleh nilai Chi Square sebesar 21,156 lebih besar dari Chi Square tabel sebesar 3,8415 sehingga dapat disimpulkan bahwa pengawasan Infection Prevention and Control Link Nurse (IPCLN) memiliki hubungan signifikan terhadap kepatuhan perawat melakukan cuci tangan di ruang rawat inap Murni Teguh Memorial Hospital Medan.

\section{SARAN}

Dari kesimpulan hasil penelitian di atas, peneliti menyarankan kepada beberapa pihak yang terlibat dalam peningkatan pengawasan Infection Prevention and Control Link Nurse (IPCLN) dan kepatuhan perawat melakukan cuci tangan di rumah sakit, yaitu :

1. Bagi Pihak Murni Teguh Memorial Hospital

Bagi Pihak Manajemen Murni Teguh Memorial Hospital

a. Memberikan pelatihan yang berkelanjutan bagi Infection Prevention and Control Link Nurse (IPCLN) agar dapat menjalankan tugasnya dengan baik.

b. Memberikan penghargaan kepada Infection Prevention and Control Link Nurse (IPCLN) yang menjalankan tugasnya dengan baik.

c. Memberikan reward dan punishment untuk meningkatkan kepatuhan cuci tangan perawat.

Kepala Bidang keperawatan

a. Kepala Bidang Keperawatan dapat mempertimbangkan tenaga Infection Prevention and Control Link Nurse (IPCLN) yang akan di mutasi agar memperhatikan pola ketenagaan Infection Prevention and Control Link Nurse (IPCLN) di setiap ruangan.

b. Kepala Bidang Keperawatan dapat memenuhi kekurangan tenaga perawat diruang rawat 
inap 3A West dan di ruang 5 West.

c. Kepala Bidang keperawatan dapat membuat program untuk mengurangi turn over tenaga keperawatan.

Kepala Ruangan

a. Kepala ruangan dapat memberikan motivasi kepada Infection Prevention and Control Link Nurse (IPCLN) agar dapat melakukan tugasnya lebih baik lagi.

b. Kepala ruangan dapat memberikan motivasi kepada perawat agar dapat meningkatkan kepatuhan melaksanakan cuci tangan

2. Infection Prevention and Control Link Nurse (IPCLN)

a. Perlu mengembangkan kompetensi dalam melaksanakan tugas sebagai Infection Prevention and Control Link Nurse (IPCLN).

b. Mengoptimalkan peran Infection Prevention and Control Link Nurse (IPCLN) untuk meningkatkan kepatuhan cuci tangan perawat dan pelaksanaan program pencegahan dan pengendalian infeksi lainnya.

Perawat Pelaksana

a. Meningkatkan motivasi diri, sikap dan tanggung jawab untuk melakukan cuci tangan sesuai dengan 5 moment for hand hygiene demi keselamatan pasien dan keselamatan diri sendiri.

3. Institusi Pendidikan

Penelitian ini diharapkan bahan bacaan bagi mahasiswa keperawatan dalam menambah pengetahuan tentang hubungan pengawasan IPCLN terhadap kepatuhan cuci tangan perawat di ruang rawat inap.

4. Bagi Peneliti Lain Penelitian ini diharapkan dapat menjadikan peneliti selanjutnya untuk mengetahui bagaimana proses pengawasan IPCLN terhadap perawat di ruang rawat inap.

\section{REFERENSI}

Al-Assaf, A. F. (2009). Mutu pelayanan kesehatan: perspektif international. Jakarta: Sagung Seto.

Arikunto, S. (2010). Prosedur penelitian : Suatu Pendekatan Praktik (Edisi Revisi). Jakarta : Rineka Cipta.

Arwani \& Supriyanto. (2006). Manajemen keperawatan di bangsal. Jakarta.

Azwar, s. (2007). Penyusunan skala psikologi. Yogyakarta: Pustaka Pelajar.

Black, Jacquelyn G. 2012 Microbiologi principles and exploration. $8^{\text {th }}$ edition. Wiley.

Damanik SM. (2011). Kepatuhan hand hygiene di Rumah Sakit Immanuel

Bandung. (tesis). Universitas Padjajaran, Bandung.

Dharma, K. K. (2011). Metodologi penelitian keperawatan: Panduan melaksanakan dan menerapkan hasil penelitian. Jakarta: Trans Info Media.

Darmadi. (2008). Infeksi nosokomial: Problematika dan pengendalian. Jakarta: Salemba Empat.

Depkes dan Perdalin. 2011. Pedoman Manajerial pencegahan dan pengendalian infeksi di Rumah Sakit dan Fasilitas Pelayanan Kesehatan lainnya. Jakarta : Direktur Jendral Bina Pelayanan Medik.

Depkes. RI. (2008). Pedoman Pencegahan dan pengendalian infeksi di Rumah Sakit dan Fasilitas Pelayanan Kesehatan Lainnya. Jakarta.

Emaliyawati. (2010). Tindakan kewaspadaan universal sebagai upaya untuk mengurangi resiko penyebaran infeksi. Bandung : FIK Univ. Padjajara

George R Terry. (2006) Prinsip-prinsip Manajemen (edisi bahasa Indonesia) PT. Bumi Aksara Bandung. 
Griffith, Peter., Renz Anna., Rafferty Anne Marie. (2008). The impact of organization and management factors on infection control in hospital : a Scoping Review, London : King's College London, University of London.

Hanifah, H. (2015). Hubungan pengawasan kepala ruang dengan tingkat kepatuhan perawat dalam penggunaan glove pada tindakan injeksi di rsud wonosari. Laporan Penelitian. Yogyakarta : Program Studi Ilmu Keperawatan, Sekolah Tinggi Ilmu Kesehatan 'Aisyiyah.

Lankford, M. G., Zembower, T. R, Trick, W. E., Hacek, D. M., Noskin, G. A. dan Peterson, L. R. (2003). Influence of role models and hospital design in the hand hygiene of health-care workers. Journal of Emerging Infectius Disease, 9: 217-223.

Oliverira, A.C., Cardoso, C.S., Mascarenhas, D. (2010). Contact precaution in intensive care units: facilitating and inhibiting factors for professionals' adherence, 44(1):159-63.

Pan, A; Placido Mondello; Klara PosfayBarbe; Patrizia Catenazzi; Annise Grandi; Silvia Lorenzotti; Andrea Patroni; Nadia Poli; Laura Soavi; Giuseppe Carnevale (2007). Hand hygiene and glove use behavior in an Italian Hospital, infection control and hospital epidemiology, Vol. 28, No. 9, pp.1099-1102.

Poerwadarminta, W.J.S. (2008). Kamus besar bahasa indonesia. Jakarta: Balai Pustaka.

Perdalin, (2010). Handout pengendalian infeksi nosocomial. Jakarta.

Perry, A.G., \& Potter, P.A. (2006). Buku ajar fundamental keperawatan: konsep, proses dan praktek. Edisi ke 4,. Jakarta: EGC.

Saefudin. Dkk (2006). Pelayanan Kesehatan Maternal dan Neonatal, Jakarta: JNPKKR dan Yayasan Bina Pustaka Sarwono Prawirohardjo.
Saparwati, M. dan W. Siswanto, 2016. Hubungan kualitas supervisi kepala ruang terhadap kepatuhan perawat melakukan standar cuci tangan di instalasi rawat inap RST Dr. Soedjono Magelang. Jurnal PSIK STIKES Ngudi Waluyo Ungaran.

Simanjuntak, P. 2011. Manajemen dan Evaluasi Kinerja. Jakarta : Lembaga Penerbit Fakultas Ekonomi Universitas Indonesia.

Smet, Bart. 1994. Psikologi kesehatan. Jakarta: Grasindo.

Sugiono. (2009). Metodoligi Penelitian. Jakarta: Alfabeta.

Suharsimi, A. (2006). Prosedur penelitian suatu pendekatan praktek. Jakarta: Rineka Cipta.

Sukardi (2011) Metodologi penelitian pendidikan. Jakarta: Bumi Aksara.

Sumantri, A. (2011). Metodologi penelitian kesehatan. Jakarta: Kencana.

Susiati. (2008). Keterampilan keperawatan dasar, Paket 1, Erlangga Medical SERIES, Jakarta

Susilo, Joko. (2009). Kepatuhan mencuci tangan pada perawat yang telah mengikuti pelatihan pencegahan pengendalian infeksi nosokomial di Rumah Sakit Jantung Dan Pembuluh Darah Harapan Kita Tahun 2009. Skripsi. FKM UI Depok.

Tietjen, L., Bossemeyer, B., \& Mclntos, N., (2004). Panduan pencegahan infeksi untuk fasilitas pelayanan kesehatan. Yayasan Bina Pustaka Sarwono Prawirohardjo. Jakarta.

WHO. (2006). WHO Guidelines on Hand Hygiene in Health Care a Summary (AdvanceDraft)WHO/EIP/SPO/Q $\mathrm{PS} / 05.2$.

WHO. (2009). WHO Guidelines on Hand Hygiene in Health Care a Summary.WHO/IER/PSP/2009.0. 